\title{
Misleading about MBT in Oslo
}

\author{
Sigmund Karterud ${ }^{1 *}$ (D) and Elfrida Hartveit Kvarstein ${ }^{2}$
}

\begin{abstract}
In this correspondence we correct some misleading information about mentalization-based treatment in Oslo, Norway.
\end{abstract}

Keywords: Mentalization-based treatment, Borderline personality disorder, Correction

\section{Main text}

We are very much in sympathy with the therapeutic project, mentalization-based treatment (MBT) for borderline patients, recently being reported by our Swedish colleagues Löf et al. [1] in BMC Psychiatry. However, we have to correct some misleading information that Löf and coworkers convey about one of our previous studies [2]. Our study concerned 64 borderline patients who had received MBT and who were compared to a representative sample of 281 borderline patients who had received psychodynamic treatment. Löf et al. [1] have some critical remarks to this study. They assert 1) that our sample was not "community-based" (p. 2), 2) that it was "not clear how BPD diagnosis was established, nor whether diagnoses were valid and reliable since no information was provided on possible exclusion criteria" (p. 2), and 3) that the effect size (EZ) of our study on "general psychiatric symptoms" (SCL-90R) was 1.05 (p. 7).

These assertions are incorrect. In our publication we 1) report that patients were referred to specialist outpatient treatment in Oslo, the sample thus being "community- based" (p. 3). In fact, the outpatient department had a regional responsibility for the city of Oslo. Based upon our original text, this might be a misunderstanding from Löf et al. It is harder to understand the reasons for the next points. 2) Under the heading "Diagnostic skills and reliability" we report that all patients were diagnosed with SCID-II interviews and we even report the reliability of the procedure (p. 4). 3) On p. 8 we report that the effect size of general psychiatric symptoms (brief version of SCL-90R) was 1.79 (not 1.05).

Towards the end of their article, Löf et al. [1] discuss their effect size $(\mathrm{d}=0.58)$ on psychiatric symptoms. It seems unwarranted to compare it with ours $(d=1.79)$, since ours is an estimate at 3 years for a treatment program that lasted up to 3 years, while the Swedish program terminated after 18 months. As the authors write, psychiatric symptoms might decline even after termination of psychotherapy. However, a sounder way to increase treatment results, would be to prolong treatment time. This is not so costly if one invests in mentalization-based group psychotherapy (MBT-G).

\section{Authors' response}

\section{David Clinton}

Thank you for the opportunity of replying to the points raised by our discussion of Kvarstein et al (2015) [2].

Prof. Karterud is right that we failed to report the correct effect size from their study in relation to changes in the BSI-18, which should be $d=1.79$ instead of $d=1.05$ for MBT patients. We sincerely apologise for this mistake. However, we take issue with their other

\footnotetext{
* Correspondence: wkarteru@online.no

${ }^{1}$ Institute for Mentalizing, Svartediksveien 6a, 5009 Bergen, Norway

Full list of author information is available at the end of the article
}

contentions that we present "incorrect" information about their study. Our discussion reflects the fact that the paper by Kvarstein and colleagues fails to provide sufficient clarity about their methods and results. Accordingly, we believe that a reasonable scientific approach should be to interpret the quality of their work conservatively.

As regards the question of the community-based nature of their sample, Prof. Karterud writes that the outpatient department to which patients were referred 
"had a regional responsibility for the city of Oslo". This fact is, however, missing from their report. In the paper the authors say little about the unit where patients were treated and it's relation to the health service. They do not elaborate on the selection process, how it was carried out, what sort of referral system was used, and whether the selection system remained the same during the long period that the study covers. Such information is essential for judging whether their study comprised a representative community-based sample.

Neither is it clear, as we point out, how BPD diagnoses were made, nor whether diagnoses were valid and reliable. It is true that the authors used SCID-II interviews at baseline, and reported kappa for BPD. However, they use an extremely small sub-sample comprising 24 of 345 patients for estimating reliability. We have no way of knowing how representative these 24 patients were, how well the remaining 321 cases were diagnosed, or whether specific exclusion criteria were applied to the sample as a whole or during particular periods. All the authors report is that a few patients were excluded due to participation in an RCT, while others were excluded during a transitional period. The study covers patients treated over a 20 -year period, but there is no information about how the quality of BPD diagnoses and psychiatric assessment might have varied during this period, raising further questions about the reliability and validity of diagnoses.

Prof. Karterud raises questions about comparing effect sizes in our two studies. Although comparisons are made more difficult by the differing lengths of treatment in the studies, as Prof. Karterud points out, conclusions regarding effect sizes in Kvarstein et al are hampered by the lack of clarity about the number of persons their pre-post comparisons are based on. A strength of our study is that our flowchart contributes to a high degree of transparency. Kvarstein et al report percentages under "repeated outcome assessments", but it is not known who is being compared, and whether the high effect size they report could be due to the authors following up the healthiest patients (i.e. possible selection bias).

In sum, although we did regrettably make a mistake in our reporting of effect size from Kvarstein et al, we believe that the authors make important methodological omissions in the reporting of their data that allow for questions to be raised about the community-based nature of their sample, the validity and reliability of BPD diagnoses, and the relevance of their effect sizes.

\section{Abbreviations}

BPD: Borderline personality disorder; EZ: Effect size; MBT: Mentalization-based treatment; MBT-G: Mentalization-based group psychotherapy
Authors' contributions

Both authors contributed equally to writing the manuscript. All authors read and approved the final manuscript.

Author's information

Associate Professor of Medical Psychology, Clinical Psychologist, Psychotherapist, Psychoanalyst (IPA)

Funding

None.

Availability of data and materials

Not applicable.

Ethics approval and consent to participate

Not applicable.

Consent for publication

Not applicable.

Competing interests

The authors declare that they have no competing interests.

Author details

${ }^{1}$ Institute for Mentalizing, Svartediksveien 6a, 5009 Bergen, Norway. ${ }^{2}$ Oslo University Hospital, Kirkeveien 144, Oslo, Norway.

Received: 30 October 2018 Accepted: 23 June 2019

Published online: 04 July 2019

References

1. Lof J, Clinton D, Kaldo V, Ryden G. Symptom, alexithymia and self-image outcomes of Mentalisation-based treatment for borderline personality disorder: a naturalistic study. BMC Psychiatry. 2018;18(1):185.

2. Kvarstein EH, Pedersen G, Urnes O, Hummelen B, Wilberg T, Karterud S. Changing from a traditional psychodynamic treatment programme to mentalization-based treatment for patients with borderline personality disorder--does it make a difference? Psychol Psychother. 2015;88(1):71-86

\section{Publisher's Note}

Springer Nature remains neutral with regard to jurisdictional claims in published maps and institutional affiliations.

Ready to submit your research? Choose BMC and benefit from:

- fast, convenient online submission

- thorough peer review by experienced researchers in your field

- rapid publication on acceptance

- support for research data, including large and complex data types

- gold Open Access which fosters wider collaboration and increased citations

- maximum visibility for your research: over $100 \mathrm{M}$ website views per year

At $\mathrm{BMC}$, research is always in progress.

Learn more biomedcentral.com/submissions 